\title{
La Conferencia Regional Europea del Trabajo
}

\author{
por el Dr. JOSE LUIS BUSTAMANTE Y RIVERO
}

Del 24 de enero al 5 de febrero de 1955 se reunió en Ginebra la I Conferencia Regional Europea, promovida por la Organización Internacional del Trabajo con el propósito de contribuir a los esfuerzos que, desde la terminación de la segunda guerra mundial, vienen realizándose para rehacer la Europa desangrada y empobrecida y para levantar su nivel económico, gravemente venido a menos por la influencia aniquiladora de esa contienda.

A partir de 1945, esos esfuerzos se han plasmado en la creación de entidades e instituciones cuyo denominador común consiste en concretar métodos de cooperación entre los países europeos para forjar las bases de un futuro federalismo económico, de una gran economía de conjunto. Dentro de las circunstancias políticas imperantes en los últimos diez años, este empeño integralista no ha logrado siempre alcanzar proyecciones continentales o ecuménicas y se ha expresado en el intento de organizar por lo menos dos economías regionales: la de la zona occidental o "pequeña Europa" y la de la Europa oriental.

Como institución de alcance pan-eurcpeo cabe mencionar la Comisión Económica para Europa (CEE), desprendida del Consejo Económico y Social de las Naciones Unidas a inspirada primitivamente en el designio de promover la reconstrucción de los países devastados por la guerra. Después, esta finalidad se ha deslizado hacia el fomento de intercambios comerciales entre la Europa Occidental y la Oriental.

Como, instituciones regionales se cuentan, en la Europa Occidental:

La Organización Europea de Conperación Económica (OECE), encaminada a regir y supervigilar la aplicación del Plan Marshall y a revitalizar la industria de producción para crear fuentes de trabajo;

La Unión Occidental u Organizcción del Tratado de Bruselas (UO), con aspectos políticos y militares de defensa, pero poseedora, además, de un Comité Social, cuyos fines son promover el alza de nivel de vida de las poblaciones de los cinco Estados Asociados (Francia, Bélrica, Holanda, Luxem- 
burgo y Gran Bretaña) y desenvolver en ellos los servicios sociales y de seguridad social;

El Consejo de Europa (CE), cuyos quince Estados componentes, aparte de otros objetivos de unidad en la acción política, se proponen salvaguardar y promover su patrimonio común y favorecer su progreso económica y social;

La Comunidad Europea del Carbón y del Acero (CECA), constituída por la Alemania Federal, Francia, Bélgica, Países Bajos, Luxemburgo a Italia, quienes mediante el establecimiento de un mercado común de esos productos, aspira a contribuir a la expansión económica, al desenvolvimiento del empleo y al mejoramiento del nivel de vida en los Estados Miembros:

El Comité Intergubernamental para las Migraciones Europeas (CIME), institúdo para estudiar los medios de atenuación del problema de la congestión demográfica y prestar facilidades al transporte de trabajadores europeos deseosos de emigrar a otros continentes.

En la Europa Oriental funciona el Consejo de Assistencia Económica Mutua, del cual son miembros la Unión. Rusa Soviética, Polonia, Bulgaria, Hungría y Checoeslovaquia y que está dirigido a estrechar la cooperación económica entre esos países mediante la asistencia técnica, el intercambio de experiencias económicas y la ayuda mutua en cuanto a la provisión de materias primas, productos alimenticios $\mathrm{y}$ equipos mecanizados.

Pero todos estos intentos de colaboración recíproca con vistas a unificar o complementar las economías nacionales en una síntesis continental o, por lo menos, regional tropiezan en la práctica con el estorbo de las diferencias existentes en las condiciones demográficas y sociales de cada país, en la pugna de sus sistemas aduaneros, en la heterogeneidad de sus nivéles de vida y escalas de salarios y en la diversidad de los índices de desocupación y del alcance de los beneficios de la seguridad social. Buscar puntos de coincidencia y una creciente armonización práctica de estos elementos en los diferentes pueblos aceleraría, sin duda, Ia tarea de las instituciones que propicion la idea de una Europa económicamente integrada y cutártica. Ninguna entidad mejor preparada para realizar esta labor de aproximación, coordinación y ensambladura que la OIT, la cual, desde hace más de treinta años, actúa en el plano internacional en contacto directo con las fuerzas vivas de la empresa y el trabajo, con sus problemas peculiares y con lós avances de la legislación social. Tal ha sido el origen de la I Conferencia Regional Europea del Trabajo.

La Agenda del certamen contenía puntos de palpable vigencia en el actual proceso de resurgimiento económico de Europa: la situación general del empleo y los problemas de la mano de obra; el desarrollo de las relaciones profesionales y de la libertad sindical; el problema del alojamiento como secuela de la guerra en el período de post-guerra; el papel de los empleadores y trabajadores en el programa de incremento de la productividad en Europa; los métodos de provisión de fondos para la seguridad social; la fijación de la edad de retiro del trabajador; etc. Todos estos temas han sido objeto de estudio y discusión en las comisiones de la Con- 
ferencia $Y$ en sus reuniones plenarias; $y$ si bien los resultados distan mucho de entrañar en la mayoría de los casos soluciones definitivas - qua la complejidad de los asuntos no permitía esperar- es indudable que se ha avanzado no poco en el análisis de los problemas y en la puntualización de los métodos que todos - Gobiemos, empleadores $y$ trabajadores- han de poner en obra para alcanzar los tines perseguidos.

No pretende, sin embargo, este artículo entrar a fondo en las conclusiones de la Conferencia. $Y$ es que dentro de ella se produjo un episodio que, pese a su carácter aparentemente procesal o formal, tiene una trascendencia mayor que los temas de la Agenda misma y puede repercutir decisivamente en la estructura y en la eficiencia del Organismo Intemacional del Trabajo como rebote de la pugna ideológica entre Oriente y Occidente. Al relato y examen de ese episodio ha de concretarse esta crónica.

Como es sabido, el nacimiento de la OT se remonta a la época de la liquidación de la primera guerra mundial (1919). Surgida como una de las ramas de la fenecida Liga de Naciones, fue quizás la única de sus instituciones que realizó una labor realmente constructiva para la reorganización social del mundo y que sobrevivió al fracaso político del Organismo Wilsoniano. Sobrevenida la segunda guerra mundial y echadas en la Conferencia de San Francisco las bases de la nueva Organización de las Naciones Unidas, se. hizo honor a la actuación anterior de la OIT y se la consideró como dependencia incluída en el flamante Organismo mundial. Al ser revisada su constitución en el año 1946, quedó establecido que los Estados-miembros de Ia ONU gozaban, por ese sólo título, de la opción a ser aceptados como miembros de la OIT. Sin embargo, durante varios años, la U.R.S.S. y otros de los Estados adscritos al régimen de las demacracias populares se abstuvieron de ingresar a este organismo técnico o pretendieron ser admitidos en él bajo reserva del repudio de algunas de sus normas constitucionales; pretensión que les fue denegada. Sólo en 1954 la U.R.S.S. retiró sus condiciones y solicitó su admisión con reconocimiento de la Carta de la OIT. Otorgado el pedido, se sucedió luego el ingreso de los otros Estados hasta entonces abstinentes.

Es del caso recordar que el funcionamiento de la OIT reposa, según sus constituciones, en el régimen llamado del "tripartismo" o sea de una triple representación de los Empleadores, de los Trabajadores y de los Gobiernos. Se quiso dar así ingerencia en el estudio y solución de los problemas mundiales del trabajo a los tres elementos que intervienen en la producción: el Capital, el Trabajo o Mano de Obra y la Autoridad, que planifica y regula las relaciones entre los otros dos grupos. El grupo de Delegados Gubernamentales procede de nombramiento; en tanto que los dos restantes se constituyen a base de elecciones de los gremios o sindicatos libres de empleadores y de dependientes (empleados $\mathrm{y}$ obreros). Reconócese en principio a cada grupo autonomía de actuación en el ejercicio de sus funciones dentro de la OIT, en consonancia con el postulado de la libertad sindical. 
Según la opinión soviética, la estructura de la OIT está vaciada constitucionalmente en los moldes del régimen capitalista que admite la libre empresa privada, la autonomía del capital, el contrato de trabajo y la libertad sindical; figuras jurídicas todas ellas que, lejos de acomodarse, se oponen a las normas colectivistas del monopolio estatal de la empresa, la nacionalización de los medios de producción, el trabajo obligatorio al servicio del Estado $y$ el régimen oficial o dirigido de los sindicatos. He aquí la razón de las reservas que el esquema estructural de la OIT inspiraba a la Unión Soviética.

Con la entrada a este Organismo de los Estádos de régimen colectivista quedó, pues, planteada de hecho en 1954 la divergencia entre el sistema de política social de esos Estados $\mathrm{y}$ el dispositivo de las fuerzas del trabajo en el seno de la Institución especializada del ramo. Uno de los primeros casos en que ha buscado expresión esa divergencia acaba de darse en la I Conferencia Regional Europea.

Acudieron $\alpha$ este certamen 25 países europeos, cuyos delegados estaban repartidos - como es norma invariable en las reuniones de la OIT- en los tres grupos clásicos: 49 delegados gubernamentales, 25 delegados de los empleadores y 25 delegados de los trabajadores. Instalada la Asamblea, y al tiempo de ser designado el personal de las comisiones de trabajo, el grupo de empleadores se abstuvo de proponer para integrarlas a ninguno de los delegados de los empleadores de la Europa Oriental. Las comisiones quedaron, pues, formadas en lo que concierne $\alpha$ este grupo, exclusivamente por delegados de empleados occidentales. Reglamentariamente hablanda, no había en ello anomalía alguna; pues siendo numerosos los Estados concurrentes $Y$, en cambio, muy limitado el número de comisia nes y el de plazas disponibles en cada una de éstas, habría existido imposibilidad material de que todos los países estuviesen representạdos en alguna comisión. Sólo algunos de entre ellos podían ser designados; y esa designación es libre. No hay agravio para quien no resulta favorecido.

Pero en vista de este resultado, los delegados de los empleadores de la Europa del Este solicitaron ante la Comisión de Proposiciones que se admitiese a algunos de ellos como miembros suplentes de las comisiones de Productividad, Edad del Retiro y Seguridad Social. Los suplentes, según el Estatuto, tienen derecho a voz, pero no a voto. Aunque el pedido fue rechazado por mayoría en la Comisión de Proposiciones, el grupo gubernamental, apoyando una propuesta del representante del Gobiemo del Reino Unida, decidió hacer suya la demanda de los delegados de los empleadores orientales $\mathrm{y}$ plantear ante la Conferencia en Pleno la designación de suplentes.

Tocó al Presidente de la Conferencia, M. Ramadier, Delegado de Francia, sostener la proposición en nombre del grupo gubernamental; y lo hizo con brillantez y mesura. Fn un debate vivo $y$, por momentos, agresivo y dramático, el grupo de empleadores, dividido en dos bandos, hizo vibrar en la Sala su oratoria encendida. Acerbas críticas $Y$ argumentaciones contrapuestas dieron a la polémica interés y pasión. Hubo lances de esgrima in- 
telectual de positiva fuerza en el impacto. $Y$, al final, la Conferencia acogió por mayoría la moción británica, aceptando la designación de miembros suplentes en favor de delegados empleadores de Bielorusia, Bulgaria, Polonia, Checoeslovaquia, Unión Soviética y Ucrania.

La reacción del grupo de delegados empleadores de la Europa Occidental fue su retiro del seno de todas las comisiones hasta el fin de la Conferencia. No podían - dijeron-alternar con quienes no representaban reclmente a empleadores libres.

Interesa sobremánera en este asunto conocer los puntos le vista de ambas partes contrincantes, no sólo para medir el alcance del problema que se plantea a la OIT, sino porque el episodio recién descrito viene $\alpha$ reflejar en escala reducida ese otro gran problema que atenaza de angustias el mundo contemporáneo y que consiste en la dualidad, hasta hoy poco menos que inconciliable, de dos ideologías y dos sistemas político-sociales inscritos, sin embargo, dentro de un solo panorama humano, sobre una misma tierra $\mathrm{y}$ bajo un mismo sol.

Como argumentos en contra de la admisión de delegados patronales del Este a las suplencias de las comisiones fueron aducidos, entre otros, los siguientes:

1) Descie su creación, en 1919, la OIT fue concebida como una entidad de composición tripartita, con representación separada e independiente de los Empleadores, de los Trabajadores y de los Gobiemos. Una invariable tradición institucional ha reconocido desde entonces la autonomía de cada uno de los tres grupos, así en lo referente a la designación de sus delegados como en lo tocante al sentido de sus decisiones. Viene a romper esa autonomía el hecho de que en esta Conferencia, ingiriéndose en asuntos de un grupo ajeno, los representantes gubernamentales y los de los trabajadores, o algunos de ellos, intenten completar el personal de las comisio nes con delegados suplentes extraídos del grupo de empleadores; $y$ eso con el agregado de que los candidatos a las suplencias no cuentan con la confianza del grupo empleador mayoritario. Tal ingerencia envuelve un ataque al régimen tripartito y a la independencia de los grupos.

2) Por su índole propia, los regímenes de dictadura totalitaria son incompatibles con el sistema de representación tripartita de la OIT; pues éste último supone la existencia de fuerzas sociales (Capital y Trabajo) orgánicamente separadas del gobierno, que no emanan de él y que poseen vida y autonomía propias aunque estén sometidas a la ley: en tanto que dentro de aquellos regímenes todas las fuerzas sociales dependen económica, técnica y administrativamente del Poder Político, en el cual se centraliza su dirección integral. Por eso las delegaciones de países totalitarios no son tripartitas: son delegaciones monolíticas. El gremio de empleadores no existe allí, propiamente hablando; pues involucrados en el Estado la posesión del capital y el monopolio de la empresa, resulta que el Estado es el único empleador y los delegados que pueda enviarse a conferencias como la presente en nombre de las empresas de Estado no serán, en rigor, delegados patronales, sino gubernamentales. Así, en el caso de 
la OIT, el número de delegados gubernamentales de las dictaduras del Este queda automáticamente elevado al doble de los delegados de Gobiemos occidentales. Con todo lo cual queda roto el "tripartismo".

3) La libertad de determinación ha sido siempre una de las características del sistema tripartito de la OIT: Libertad en los gremios para el nombramiento de sus delegados; libertad en estos últimos de opinión y de voto. Ahora bien: ¿Cómo conciliar este principio de libertad al cual se atiene y dentro del cual actúan los empleadores y delegados occidentales con los principios de imposición autoritaria y de obediencia ciega que rigen en los páses totalitarios de la Europa Oriental? ¿Cómo puede obligarse a los delegados de los empleadores de Occidente, hombres libres personeros de patrones libres, a sentarse lado a lado de otros representantes cuya nominación se hizo, no por elección, sino a mérito de órdenes incontrastables e irrenunciables y cuyo criterio y votaciones se ajustan a consignas rígidas impartidas desde las alturas del poder? ¿Qué puntos de coincidencia pueden encontrarse entre unos y otros? ¿Cómo pueden discutir fructuosamente alrededor de una mesa personas educadas dentro de un sistema de libertad individual y gremial y personas subordinadas a un régimen donde impera la aulocracia en el manejo de la empresa y el trabajo forzado? Semejante situación destruye por su base los principios liberales de la representación tripartita y deprimen el valor de la persona humana. Los votos de los delegados totalitarios son votos de acatamienio, en los que la conciencia individual o el legítimo interés del grupo no cuentan para nada.

4) La esterilidad consiguiente a esta falta de libertad en el personal de las delegaciones de la zona oriental se ha puesto en evidencia en esto mismo certamen. Invariablemente, los delegados de esa zona, cumpliendo la consignia recibida, se han ocupado ante todo de cuestiones de propaganda política ajena por entero a los fines técnicos de la convocatoria. En sus discursos, los delegados totalitarios se han dedicado a fustigar el "imperialismo económico" de los Estados Unidos, el Pacto del Atlóntico, el rearme de Alemania y los acuerdos de París, temas cuya solución no es del resorte ni está en manos de la OIT. Lejos de venir a buscar entendimientos técnicos en el ramo del trabajo, esos delegados trajeron a Ginebra agresividad $\mathrm{y}$ vientos de fronda, bajo las directivas de Moscú. $\mathrm{Y}$, sin embargo, se habla de la necesidad de una política de "co-existencia" entre el Este y el Oeste.

5) En apoyo de la inclusión de los delegados orientales en las comisiones se ha invocado el carácter de universalidad que debe tener la OIT. Ciertamente, es ésta una aspiración muy loable, pero que sólo puede dar frutos a base de una actitud unánime de buena fe $\mathrm{y}$ de observancia de las normas de la Institución. Por lo demás, es inexacto suponer que la nota de universalidad es constitucional de la OIT. El Estatuto establece que para ser admitido como miembro de la Organización se necesita una mayoría de dos tercios de los votos de la Conferencia o Asamblea General; de donde se sigue que puede haber Estados a quienes les sea denegado el ingreso. $Y$ esto es perfectamente explicable; pues para pertenecer a la OIT 
no basta ser miembro de la ONU, sino que es menester, además cumplir otras condiciones entre las cuales figura la de adherir previamente a las normas estatutarias. Una de ellas es, precisamente, la de la representación tripartita. Semejante adhesión parece parcialmente irrealizable por parte de los Estados totalitarios. Pueden éstos, sin duda, constituir delegados gubernamentales, sin que quepa formularles objeción alguna; pero como dichos Estados carecen de empleadores libres, estón en lo imposibilidad de designar representantes de ese grupo. Si quien los nombra es el Gobiemo, director de la empresa, tales representantes lo serán de las autoridades oficiales, mas no de los empleadores. He ahí suficientemente explicada la actitud de los delegados patronales de Occidente en esta Conferencia Regional. (1)

En pro de la admisión de los delegados suplentes de la zona oriental fueron aducidas estas razones:

a) El problema que aquí se debate es en el fondo el de la unidad de la OIT, dependiente e íntimamente vinculado al principio de la universalidad en que se funda la estructura de la Institución. Para alcanzar sus fines de mejoramiento social que son, en definitiva, fines humanos, la OTT aspira a reunir en su seno a todas las naciones del globo, para aumar el esfuerzo de todas ellas con miras de coordinación en los niveles económicos. y de aliento de la justicia social. No es posible conseguir tal finalidad sin un contacto comprensivo entre los representantes de todos esos pueblos. Descartar el universalismo puede significar el fracaso de la obra de la OIT.

b) Dentro de la OIT, como institución universal que es, tienen que estar representados países de civilización, historia, costumbres y orientaciones diferentes, y $\alpha$ veces hästa opuestas. No tendría, pues, este Orgá nismo ningún sentido ni razón de existir si en presencia de tales diferencias hubiera de renunciar a la realización de sus fines. Es claro que ha de tratar de aproximar criterios, reducir antagonismos, ensayar transacciones, avanzar paso a paso en una especie de tentativa de armonización de las legislaciones sociales, sin quiebra sustancial de los principios, para llegar a conseguir en las relaciones de la producción y el trabajo ese desideratum del bienestar material $\mathrm{y}$ del trato justo que constituye uno de los soportes de la paz social.

c) Lejos de ser un obstáculo, la divergencia de opiniones, de principios $y$ de métodos es una ventaja y un motivo de esclarecimiento $y$ de progreso. Todos tendrón algo útil que aportar. Compulsando argumentos, controntando instituciones dispares, cambiando informaciones mutuas sobre las realizaciones logradas y sobre las decepciones sufridas, es como puede hacerse luz en la controversia, abrirse las ojos a nuevas verdades, descubrirse

(1) Como líderes del punto de vista occidental, intervinieron en este debate: $M$. Waline, Delegado de los Empleadores de Francia; M. Fennema, por los Empleadores de los Paises Bajos; Sir Richard Snedden, por los Empleadores del Reino Unido; M. Bergenstrom, por los Empleadores de Suecia; M. Kuntzchen, por los Empleadores de Suiza: M. Campanella, por los Empleadores de Italia; M. Losaker, por los Empleadores de la República Federal Alemona: M. Pinto Coelho, Delegado Gubernamental del Portugal. 
puntos de vista no percibidos antes, convencer al contrinconte de su error y lograr, por esas vías, una depuración paulatina, un avance hacia lo mejor, una selección de conclusiones comunes, una generalización de instituciones $y$ de procedimientos, una convivencia equilibrada en que, pese $\alpha$ las disidencias que puedan subsistir, haya un común denominador de buena fe, de humanismo, de determinados objetivos prácticos y cun de ciertos principios éticos y jurídicos.

d) La negativa a ensayar el diálogo y a explorar aproximaciones susceptibles de llevar a un entendimiento siquiera parcial, determina una seric responsabilidad por cuanto entraña un motivo de agravación de la tensión presente. El mundo no puede indefinidamente mantenerse dividido en dos bandos hostiles que se acechan. Conversar, discutir, conciliar si es posible en lo accesorio no significa renunciar a los principios ni ceder en lo sustancial. En Occidente, la idea de "apaciguamiento", por el simple hecho de aludir a recientes sucesos históricos que se reputan desgraciados, suscita. una especie de psicosis de horror. Pero no debe confundirse un mal logrado apaciguamiento político con la pacificación espiritual, que es simplemente una sana disposición de los ánimos para entenderse y convivir.

e) La Conferencia no puede sentirse satisfecha de que representantes de ciertos países, legítimamente acreditados según las normas constitucionales de la OIT, tengan cerrada la posibilidad de participar en los trabajos de lás comisiones; y eso, no en rigor por falta de vacantes, sino por razón de sus ideas políticas. Tal situación implica un dislocamiento incómodo, una presencia muda, una desigualdad inequitativa, un ataque a la libertad de pensar, un trato discriminativo que no se compadece con la calidad, común a todos, de miembros de la OIT.

f) La moción en debate no entraña 'ninguna cuestión de principio: nada tiene que ver con las diferencias ideológicas entre Oriente y Occidente. Planiea, simplemente, una cuestión de hecho, bien precisa. y concreta, $\alpha$ saber: si, por encima de las discrepancias teóricas, existe la posibilidad de un trabajo práctico en común para alcanzar resultados en pro de la paz social $y$ en beneficio del trabajādor. No se trata en la OIT de estudiar doctrinas filosóficas o de evocar la diversidad de regímenes políticos. La Organización no tiene por qué hacerlo sin salirse de su papel. Trátase sólo de encontrar un lenguaje común para entenderse sobre problemas vivos de pro ducción y de trabajo que la realidad del mundo pone delante de los ojos con variedad de matices $y$ de soluciones en cada Estado. Y que esto es factible lo demuestran concluyentemente los hechos. La U.R.S. S. comercia con Suecia, por ejemplo, pese a sus diferencias de ideología e instituciones; ambos países intercambian sus productos como compradores o vendedores normal y provechosamente, sin que para ello los suecos hayan de renunciar a sus principios sobre propiedad privada ni los rusos deban aceptar previamente la desnacionalización de sus empresas estatales.

g) Ciertamente, el "tripartismo" es el soporte de la estructura de la OIT. Esta funciona a base del trinomio: Empleador, Trabajador, Estado; elomentos en los cuales se personifican el capital, la mano de obra y la autoridad. Pero desde 1919 en que se dió a la OIT esta forma de organización. 
la evolución social del mundo ha avanzado muchas etapas y la definición de "empleador" no es ya la que era entonces. En aquella época, el emplea. dor representaba a la empresa privada capitalista. Posteriormente han surgido dos fenómenos: De un lado, se generaliza -incluso en los países capitalistas, ya socialistas, ya liberales- la tendencia a la nacionalización de los servicios públicos (comunicaciones, energía eléctrica, calefacción, etc.) y de ciertos medios de producción cuya fiscalización o control interesa al Estado (combustibles, armamentos, etc.) (2). El Estado se transforma así progresivamente en empresario. Nada hay que decir de los países en que, por imperar el régimen colectivista, la empresa privada no existe y la totalidad de la producción está nacionalizada. A la luz de estos datos, cabe asombrarse, por ejemplo, de que en la I Conferencia Regional Europea del Trabajo el grupo de empleadores de Francia no incluya representantes de las Usinas Renault, o de los Ferrocarriles Franceses, o de los "Charbonnages de France", que son empresas gubemamentales de las más poderosas del país. De otro lado, y como fenómeno que empieza a darse, no ya ien el Este de Europa, sino a título de reivindicación reclamada por ios medios sindicales de los países de Occidente, es forzoso considerar la incipiente participación, o por lo menos demanda de participación del trabajador en las utilidades de la empresa, con la obligada secuela futura de un derecho a intervenir en el control y dirección de los negocios (co-gestión). Por este solo hecho, empleados y obreros quedarían automáticamente erigidos en co-empresarios, al lado de los dueños del capital o del Estado-productor. He aquí porqué se dijo que de 1919 acá el concepto de "empleador" ha experimentado una transformación radical y que, por lo mismo, se impone una revisión del régimen tripartito de la OIT.

h) Aun admitida la legitimidad de la organización tripartita en el funcionamiento de la OIT, la verdad es que los delegados de los empleadores de la Europa Oriental no están en situación de inferioridad técnica o profesional respecto a los delegados de los empleadores occidentales. Los representantes venidos de la zona oriental son auténticos empleadores, es: peciaiistas en la dirección de empresas y en los problemas de la producción, con experiencia copiosa en la planificación y organización industriales, con millones de obreros a su cargo y en relación dicria con los sindicatos de los trabajadores. En cambio, los delegados de los empleadores occidentales suelen ser, más bien que profesionales, directivos o gerentes de empresas, meros abogados o agentes de éstas a quienes se encomienda la defensa de los intereses patronales frente a las reivindicaciones obreras, con un sentido de pugna pecuniaria antes que de cooperación social. Tales delegados, reiteradamente elegidos para las reuniones de la OIT, llegan a hacerse

(2) Con el tiempo, es de prever que ocurra lo mismo con otros renglones de la pro ducción, v.gr.: las medicinas, ciertos artículos alimenticios de primera necesidad, los mate riales básicos del vestido popular: ya que las simples medidas de vigilancia o de intervención estatal en la regulación de los precios no bastan para cortar las utilidades inmodera das del productor privadio o los abusos de la especulación, en daño de la salud y do la economía del pueblo. 
grandes expertos en los tejemanejes de las conferencias, en los recursos de los debates, en las negociaciones de pasillo; pero no gozan de verdadera libertad de criterio, como ellos presuntuosamente lo afirman, ni logran sacudirse de su rancio complejo de superioridad, ni saben de las penalidades del taller y de la fábrica, experiencia esencial para el acierto en la conducción de hombres. Desde estos puntos de vista, los delegados de los empleadores orientales poseen títulos mós sólidos que sus colegas de Occidente para intervenir en las comisiones de la Conferencia (3).

El debate, como se ve, fue exhaustivo $y$ de fondo. No dejaron los polemistas argumento por invocar. En tan copioso material habrá de espigar, sin duda, la OIT cuando tenga que encarar este problema, que algunos empleadores han calificado como "el más grave que se haya planteado en la vida de la Institución" (4) y como "bomba de tiempo cuya explosión puede socavar las bases en que ella reposa" (5). Sin caer en exageraciones sombrías o en arrebatos pasionales, hay que reconocer que la OIT está abocada a asunto de singular importancia que exige una definición. Tócale poner en salvo la unidard institucional; y para ello, pronunciarse sobre si ha llegado o no el momento de revisar los fundamentos mismos de su estructura orgánica; o en otroz términos, si los postulados que parecían inconcusos en 1919 han experimentado en los siete lustros transcurridos modificaciones de tal modo sustanciales que impongan un nuevo criterio estatutario.

Para avanzar en el camino de esta investigación. es posible encontrar preciosos elementos no sólo en el debate mismo - que acaso, por razones muy explicables, haya pecado de unilateralismo e intolerancia-, sino en el campo abierto de la realidad mundial: en ese campo de anchos horizontes donde desaparecen las líneas cartográficas que dividen el Este del Oeste y en el cual, por una especie de callada simbiosis, de recóndito sistema vascular oculto a la periferia, se van infiltrando recíprocamente experiencias, imitando instituciones y aproximando conceptos para tratar de alcanzar, por encima de los límites geográficos y de los meridianos ideológicos, el desideratum ecuménico del bienestar humano.

En este terreno realista es posible llegar a muy interesantes verificaciones. ¿No ha heredado, acaso. el régimen comunista la pujante organización de la gran empresa, pacientemente elaborada y tecnificada durante mós de un siglo por el sistema capitalista? ¿Quién no descubre, por contra, en la nacionalización de las empresas de servicios públicos y de cierta clase de industrias por el moderno Estado burgués, un ensayo parcial y tímido del monopolio estatal de los medios de producción preconizado por el marxismo? ¿Qué es el socialismo de Estado, del cual tan respetablies

(3) Defendieron en este debate la tesis del nombramiento de suplentes orientales: M. Ramadier, Delegado del Gobiemo Francés; M. Veysey. Delegado Gubernamental del Reino Unido; M. Aroutiounian, Delegado del Gobiemo de la U.R.S.S.: M. Bouladous, Delegado de los Trabajadores de Francia; y. M. Chajn, Delegado Gubernamental de Polonia.

(4) Sir Richard Snedden, Delegado de los Empleadores del Reino Unido.

(5) M. Fennema, Delegado de los Empleadores de los Países Bajos. 
ejemplos se dan en el órea de la Europa. Occidental, sino un intento de armonización entre el reconocimiento de los atributos fundamentales de la persona humana - con sus expresiones objetivas de la propiedal privada, la iniciativa individual y la libre empresa- y la necesidad de extender las funciones del Estado a actividades técnico-económicas antes insospechadas - aún a costa de ciertos recortes de la libertad- para afrontar la creciente complejidad de la vida moderna y los imperativos de la previsión social? ¿No es perceptible ya en la evolución de la burocracia de los Estados Colectivistas la aparición de una nueva clase social, llena de rasgos comunes con la burguesía demo-liberal? ¿No se usurpa $y$ se falsea el calificativo "repúblicas democráticas" en aquellos países - del Este y del Oeste- donde medran dictaduras desembozadas o encubiertas que no sólo tienen proscrita la libertad sindical, sino las más elementales libertades civiles del ciudadano? Datos y síntomas son éstos que denotan un proceso inconcluso, una alquimia cargada de fermentos, una estructura en formación. Y es que asistimos a una época de transformación social profunda iniciada en el siglo antepasado por la revolución industrial del maquinismo, continuada por la revolución en curso de la ciencia electrónica y nuclear y coronada por los avances también revolucionarios de la biología, que tienen inmediata expresión e influencia en los dominios filosóficos y sociológicos. Dentro de este proceso, los valores se transfiguran, se consagran o se desquician; infíltrase en los conceptos un dramático sentido de relatividad; log conocimientos se depuran; las nuevas civilizaciones son el filtro de los errores y verdades de las que las precedieron; la permanencia de ciertas antiguas normas convalece, pese a momentáneos eclipses; impónese, en cambio, la admisión de nuevos principios o de nuevas técnicas para legislar o encausar fenómenos sociales anteriormente desconocidos $y$, por lo tanto, no amoldables a cartabones anticuados; en cuotidiano diálogo. el pasado $y$ el futuro se interrogan en demanda de soluciones; y el resultado final de esta angustia, de este estado de ansiedad que con tanta justeza terminológica puede calificarse de "agonía humana", se resuelve a la larga en un dilema: o la simbiosis o la guerra; o un compromiso de coexistencia o la exterminación de uno de los criterios; o una serena y comprensiva selección depuradora de lo que haya de bueno y fecundo en lo tradicional $y$ en lo innovador, para construir un sistema estable $y$ actual, o una pugna intolelerante que se resuelva en la deificación del pasado o en la idolatría de la revolución.

Así estudiondo el fenómeno social, como un hecho histórico y como un estado de espíritu, no puede menos que convenirse en que desde la primera guerra mundial hasta nuestros días se han producido modificacio nes de importancia en los campos de la Economía Política y del Derecho del Trabajo. Ha aparecido la figura del Estado-empresario, a expensas del área de actividades del empleador privado. $\mathrm{Y}$ no hay, en verdad, reparo de doctrina que oponer al ejercicio de la nueva fundación por quien como el Estado es una persona jurídica perfecta. No le faltan ni la capacidad legal. ni la solvencia financiera ni la licitud de fines que se exige al em- 
presario particular. Ciertamente el monopolio estatal es odioso en cuanto entraña una severa exclusión del competidor privado: pero el fenómeno no es nuevo: en el mundo capitalista se dan empresas gigantes con más poder que un Estado, que dominan la economía de uno o varios países y regulan las arcas de más de un Gobierno (6). Hay empresas que parecen Estados y pseudo-Estados que parecen simples empresas. Será sólo la experiencia la que, a la larga, se pronuncie sobre cuál de estas dos formas de gigantismo, el oficial o el privado, realizan mejor el fin social de la producción. En otro aspecto, las finanzas públicas, que hasta ayer se apoyaban en el recurso único de la recaudación tributaria, añaden hoy al patrimonio del Estado el renglón de capitales de los monopolios del Fisco y sus rendimientos. La aparición del impuesto sobre la renta en sustitución del antiguo $\theta$ injusto tipo de impuesto sobre el consumo instituye una forma de drenaje do los beneficios del capital particular hacia el cauce de las finanzas estatales para su reversión en provecho público. Por donde se la mire, la propiedad individual experimenta, pues, una "capitis diminutio". El capital ha dejado de ser la escarapela o distintivo de una clase social y la fuente matriz de la fortuna privada exclusivamente, para convertirse en el instrumento de la producción nacional, del alza del nivel económico y del progreso general de los pueblos. En otros términos, la misión del capital se ha socializado. Paralelamente a estos fenómenos, la antigua figura clásica del emprescrio privado de carne $y$ hueso se desdobla y desdibuja. Los dos hombres que había en él fundidos en uno: capitalista y jefe de empresa, se bifurcan en la actualidad. Desde la recómara actúa el copitalista. El público suele ignorario, porque se ha escabullido voluntariamente detrás del artificio legal y poco menos que inasible de las comanditas, de los sociedades anónimas, de los "trusts", de los "holdings", de los "carteles", de los fideicomisos. Este gesto de evasión, de "camouflage", corresponde a un instintivo movimiento de defensa contra la acción intervencionista del Estado que limita y aun mutila crecientemente la libertad del capital. Y así se da la paradoja de que ése último, poderoso hoy como nunca en volumen por causa de su internacionalización y del enorme desarrollo industrial, es a la vez un perseguido, más contingente y trágil que nunca por la amenaza de las expropiaciones, el incremento de las industrias nacionalizadas y el rigor de la tributación fiscal. Mucho saben de esto los capitalistas ingleses y escandinavos sujetos al régimen socialista de sus países. En el escenario público, el viejo jefe de empresa se reencarna en figuras nuevas: directores, apoderados, gerentes técnicos y administrativos. un "estado mayor" en suma, a cuyo talento organizador se confía el negocio y que tiene a su cargo la función rectora y dinámica del mismo. Algo hay en esas altas figuras que está más cerca de la psicología del empleado que de la prosopopeya del patrón. Y son ésos los hombres que ejercen el poder de mando sobre el

(6) Las industrias de petróleo, de minerales, de maquinarias, de frutas $Y$ otros productos agrícolas, de transportes marítimos, ofrecen ejemplos de esta claso en Centro $Y$ Sud América y Asia. 
personal trabajador. Es a ellos a quienes el obrero trata e identifica, con quienes alterna y convive, sin que por lo general conozca a los verdaderos dueños de su fábrica. De ahí que, en nuestros tiempos, el término "empleador" tienda a referirse, más que al capitalista, al cuerpo directivo y técnico de la empresa; pues éste y el trabajador son los dos polos visibles de la producción. El capitalista es la pre-empresa. Su función se asimila más a la de un banquero de la industria que a la de un fautor de la producción industrial. Su dinero vale en la medida en que lo hace valer su grupo directivo. Por último, el salario no es ya un simple subsidio alimenticio- aceite lubricante del hombre-máquina - sino el valor estimativo del esfuerzo intelectual o físico del hombre-persona y, sobre todo, el emblema o signo de una forma de cooperación en la producción de bienes, géneros o mercancías útiles para la colectividad. $Y$ es en virtud de estas dos notas características del concepto salarial moderno que aparecen las modalidades del salario familiar, del descanso pagado, de las vacaciones y de la seguridad social. por una parte; y que asoman, por otra, los primeros preceptos jurídicos y los ensayos prácticos de la participación del trabajador en las ganancias de la empresa, paso preliminar de la "co-gestión" o figura del trabajador-empresario. Así visto el panorama, todo el proceso de la producción se socializa. Los diferentes elementos que en ella intervienen no son sina factores solidarios e inseparables de un mismo y único fenómeno económicosocial. Estado, empresario y trabajadores son, todos, PRODUCTORES, sin perjuicio de la privativa función legisladora del Estado. Ante esta aproximación de conceptos, de personas y de fines resultan ya discutibles las divisiones tripartitas y la hermética autonomía de grupos. Lo deseable es que todos los momentos de la producción estén presentes. $Y$ lo que fundamentalmente importa es encontrar un método de mutua inteligencia para que todos los interesados respeten y pongan a salvo los derechos de la persona humana.

Para el mundo occidental, esta aspiración está de acuerdo con su propia ideología. El Occidente cristiano, precisamente por su cristianismo, debe tender a la equidad de trato respecto del pobre y el obrero, a la supresión de todo usurario beneficio, a la ayuda fraterna del prójimo en el conjunto de la comunidad. Para el mundo comunista, la dictadura totalitario es un freno al incumplimiento por parte del capitalismo de los dictados de la justicia social; y la supresión de la libertad se dice impuesta por el abuso que de ella hicieron las clases privilegiadas. Acaso si en el diálogo de Oriente y Occidente pudieran reducirse las distancias con sólo hacerse el capitalismo más de veras cristiano, para que el comunismo, desarmado, reconociera la inutilidad de la dictadura y las excelencias de la libertad.

Cabe presumir que una visión así, objetiva, de la realidad económicosocial del mundo suministraría a la OIT útiles inspiraciones sobre la manera de abordar el re-examen de su Estatuto y decidir si ha llegado o no el momento de reformarlo. Dos son las vías que, al parecer, le están abiertas: - el mantenimiento de la estructura tripartita de la Institución, para buscar dentro de esos moldes ya tradicionales en ella el perfeccionamiento creciente del Derecho Social; o el ensayo de algún régimen nuevo de labores 
que tome en cuenta los recientes aspectos de la actividad económica del Estado y las inflexiones que asumen los elementos humanos de la producción. La primera solución implicaría, probablemente, la renuncia al principio de la universalidad; si bien podría, en cambio, provocar una estimulante competencia entre organizaciones del trabajo del Oeste $y$ del Este, con vistas a definir en cuál de los dos sistemas es más hacedero encontrar los ideales del bienestar del trabajador y de la armonía entre los grupos. sociales. Con la segunda solución, ciertamente más dificil pero de mayor alcance, se intentaría una convivencia de concepciones dispares mediante un acuerdo constructivo, rico en nobleza y selección. Pero precisa, en esta hipótesis, exigir a ambas partes una probada buena fe: de lo contrario, valiera más no intentar el experimento. Esperemos en la cordura y lucidez de la OIT al afrontar el arduo problema. De todos modos, una afirmación cabe anticipar: Cualquiera que fuere el camino por el que se optase, la justicia social se abrirá paso. Ley de la humanidad es el progreso; y desde que el mundo es mundo esa ley viene cumpliéndose inflexible, sea que avance por la ancha vía de la conciliación humana, sea que deba trasponer los obstáculos de la enemistad política, del fanatismo ideológico, del egoísmo prepotente o de la obsesión liberticida. El trabajo del hombre no puede sustraerse a esa constante de la historia. 